\title{
Recuperando espacios y resignificando el concepto patrimonio desde los movimientos sociales. El caso del CSOA La Higuera (Cádiz, Andalucía)
}

\author{
Jaime Jover Báez \\ Universidad de Sevilla. Departamento de Geografía Humana \\ jjover@us.es
}

\section{Sergio Almisas Cruz}

Universidad de Cádiz. Departamento de Historia, Geografía y Filosofía sergio.almisas@uca.es

\section{Resumen}

Las relaciones entre patrimonio histórico, sociedad civil y Estado en las ciudades históricas son de elevado interés y su estudio requiere de una visión multidisciplinar desde las ciencias sociales. Existen contradicciones entre el destino público del patrimonio garantizado por el Estado y las formas en las que la conservación y gestión del mismo se llevan a cabo, en tanto tienden a marginar iniciativas que provienen de la ciudadanía, de los movimientos sociales, y potencian aquellas orientadas a la tematización y mercantilización del mismo. Se argumenta que en estos procesos juegan un papel importante los intereses de sectores privados, que buscan su propio beneficio y se oponen al modelo social de patrimonio histórico o cultural. Frente a esta situación, se evalúa la capacidad de proyectos radicales ciudadanos en la lucha práctica frente a la neoliberalización de la ciudad histórica y sus repercusiones en el discurso teórico patrimonial a través de un ejemplo en Cádiz.

Palabras clave: teoría patrimonial; ideología; Cádiz; movimientos sociales; okupación.

Resum. Recuperant espais i resignificant el concepte patrimoni des dels moviments socials. El cas del CSOA La Higuera (Cadis, Andalusia)

Les relacions entre patrimoni històric, societat civil i Estat en les ciutats històriques són d'elevat interès i el seu estudi requereix d'una visió multidisciplinària des de les ciències socials. Hi ha contradiccions entre el destí públic del patrimoni garantit per l'Estat i les formes per les quals la conservació i la gestió d'aquest patrimoni es duen a terme, en tant que tendeixen a marginar iniciatives que provenen de la ciutadania, dels moviments socials, i per contra potencien aquelles orientades a la tematització i mercantilització d'aquest. S'argumenta que en aquests processos juguen un paper important els interessos dels sectors 
privats, que busquen el seu propi benefici i s'oposen al model social de patrimoni històric o cultural. Davant d'aquesta situació, i a través d'un exemple a la ciutat de Cadis, s'avalua la capacitat de projectes radicals ciutadans en la lluita pràctica davant la neoliberalització de la ciutat històrica i les seves repercussions en el discurs teòric patrimonial.

Paraules clau: teoria patrimonial; ideologia; Cadis; moviments socials; okupació.

Résumé. Récupération des espaces et requalification du concept de patrimoine depuis les mouvements sociaux. Le cas du Centre social squatté autogéré La Higuera (Cadix, Andalousie)

Les rapports entre le patrimoine, la société civile et l'État au sein des villes historiques soulèvent un intérêt croissant et leur étude demande une approche multidisciplinaire depuis les Sciences Sociales. Des contradictions existent entre la destination publique du patrimoine garantie par l'Etat et la mise en ouvre de sa conservation et de sa gestion: celle-ci montre une tendance à la marginalisation des initiatives provenant des habitants, des mouvements sociaux, et renforcent celles qui sont orientées vers la thématisation et la marchandisation de soi-même. Il fait valoir que dans ces processus les intérêts du secteur privé qui cherche son propre bénéfice jouent un rôle important, en opposition au modèle social du patrimoine historique ou culturel. Devant cette situation, la capacité des projets radicaux des citoyens dans la lutte pratique contre la néo-libéralisation de la ville historique et leur impact sur le discours théorique sont évalués à travers un exemple situé dans la ville de Cadix.

Mots-clé: théorie patrimoniel; idéologie; Cadix; mouvement sociaux; squat.

Abstract. Recovering spaces and resignifying the concept of cultural heritage from social movements. The case of the La Higuera self-managed social center for squatters (Cadiz, Andalusia)

The relations between historical heritage, civil society and the State in historical cities are of outstanding interest, and a multidisciplinary approach from social sciences is required to tackle them. There are contradictions between the cultural heritage public-destiny guaranteed by the State and the forms by which conservation and management have been carried out, due to the marginalization of initiatives from citizens, from social movements, whereas other initiatives fostering heritage thematization and marketization have been implemented. It is argued that these processes respond to private interests acting for their own benefit, and therefore in opposition to the socially based conceptualisation of cultural heritage. Given this situation, the capacity of radical movements and projects in the daily struggle against the neoliberalisation of the historical city is explored, focusing on the repercussions for urban heritage discourse and praxis through an example in the city of Cadiz.

Keywords: heritage theory; ideology; Cadiz; social movements; squatting.

\section{Sumario}

Introducción. Estado, movimientos sociales y patrimonio

Contradicciones conceptuales bajo el capitalismo y patrimonio urbano en tiempos de crisis

El contexto geohistórico del urbanismo gaditano en los siglos XX y XXI
Movimientos sociales y vecinales en la encrucijada urbanística y patrimonial gaditana. La okupación como respuesta El caso de «Manuel Rancés, 18» Conclusiones Referencias bibliográficas 


\section{Introducción. Estado, movimientos sociales y patrimonio}

La crisis que actualmente sacude al sistema capitalista hace necesario que cuestionemos y replanteemos, no exclusivamente como investigadores, sino como ciudadanos, las construcciones teóricas, ideológicas y prácticas que configuran a día de hoy diferentes aspectos de nuestra realidad. Con base en una crítica radical al sistema, este proceso está materializándose en la multiplicación de movimientos sociales, políticos, sindicales, etc., que no se vivía en el estado español desde la década de 1980. Entre ellos pueden nombrarse las plataformas contra las transacciones financieras internacionales como ATTAC, o a favor del derecho a la vivienda como la $\mathrm{PAH}$; movimientos contra los recortes en educación y sanidad y por unos servicios públicos de calidad, como las mareas verdes y blancas; o acciones puntuales como las llevadas a cabo por el Sindicato Andaluz de Trabajadores por una más justa redistribución de todo tipo de bienes, desde alimentos hasta tierras en desuso. Todos tienen como nexo común una demanda que consideramos fundamental, cuya finalidad estimula y justifica el presente trabajo: la recuperación de la soberanía popular en lo concerniente a los aspectos que se consideran fundamentales para la constitución de una sociedad justa, igualitaria, plural y solidaria, donde primen las necesidades humanas frente a los intereses privados.

Por nuestra parte, queremos abordar esta demanda en lo concerniente al patrimonio histórico, las políticas y la construcción teórica sobre el mismo en el contexto actual; así como la reconceptualización y usos que de él hacen movimientos sociales en la ciudad y los beneficios que para la ciudadanía puede suponer.

Para ello partimos de la teoría política que entiende el estado capitalista como la condensación política de relaciones de clase antagónicas, como actor necesario en la reproducción de las relaciones de producción mediante la organización de las relaciones político-ideológicas: «La ideología no es algo neutro en la sociedad [...] la ideología dominante, en particular, consiste en un poder esencial de la clase dominante.» (Poulantzas, 1978: 27). Una ideología que, para legitimar tal dominación, se articula con especial intensidad en el contexto global actual en torno al concepto estado-nación, permitiendo la reproducción del proyecto hegemónico que constituye y determina la acumulación y competición capitalista (Jessop, 1990; Hirsch y Kannankulam, 2011). Auspiciado por el estado-nación y usando el amplio poder de los medios de comunicación de masas, la ideología dominante actual, el sentido común neoliberal, se ha impuesto de manera abrumadora y ha permeado en la práctica totalidad de la sociedad. Así es como se ha impuesto una agenda política, económica y social donde impera la subordinación a la lógica del capital (Borón, 2003a, 2003b). Esta dinámica se traduce en múltiples formas y experiencias espaciales (Harvey, 2001, 2012; Muñoz, 2008), multiplicando al mismo tiempo las contradicciones del sistema.

Entre estas contradicciones se encuentra la mutación que ha sufrido el patrimonio urbano, cuyas transformaciones se producen a la par que otras esca- 
lares, temporales y culturales, lo que da como resultado su mercantilización, en el contexto de un urbanismo manufacturado a nivel planetario y cada día más alejado de los intereses ciudadanos. De esta forma analizaremos el caso concreto de la ciudad de Cádiz y, dentro de ella, abordaremos el destino de una casa-palacio en la calle Manuel Rancés, o cómo se ha traspasado la legalidad vigente para darle un uso social y ensayar formas nuevas de conceptualizar el patrimonio más allá de un contenido alineado con el sistema capitalista y sus fundamentos economicistas.

Por tanto, el objetivo principal de este documento no es analizar los valores patrimoniales de la casa-palacio o su repercusión como centro social okupado, sino plantear una aportación crítica acerca de la sistémica relación entre poder institucional, movimientos sociales y patrimonio urbano, ejemplificado a través del caso de Cádiz. Con ello se pretende aportar una nueva visión, tanto abstracta como concreta, de la ciudad histórica desde un punto de vista radical, y ayudar a visibilizar otra forma de comprender el patrimonio. Una visión consecuente con la realidad actual que nos empuja a proponer alternativas a los estudios que, desde las diversas disciplinas que analizan la ciudad, normalmente reducen cuestiones de patrimonio y urbanismo a asuntos técnicos, estéticos, económicos, etc., sin entrar a valorar su proyección social y su entronque con relaciones de poder entre grupos sociales o intereses e ideologías subalternos frente a las hegemónicas.

\section{Contradicciones conceptuales bajo el capitalismo $y$ patrimonio urbano en tiempos de crisis}

El nexo que conceptualmente define las ciudades históricas, o al menos una parte de ellas, es el patrimonio histórico o cultural. Se entiende que determinados espacios urbanos, públicos y privados, poseen unos valores, materiales e inmateriales, que merecen ser tutelados por los poderes públicos. En el mundo occidental, ello deriva de la vocación universal y democrática de dichos valores (Castillo Ruiz, 2007), que ya a principios del siglo Xx teorizó Alois Riegl (Arjones Fernández, 2007; Castillo Ruiz, 2005), y que culminaría en la teoría de los bienes culturales (Giannini, 1976) ${ }^{1}$. Esta entiende que los valores patrimoniales tienen un carácter colectivo, defendidos por el Estado en tanto que articulación cultural de, por y para el pueblo. Así, el interés por la defensa y promoción del patrimonio es público (Alonso Ibáñez, 1992). No sólo tenemos derecho a conocer nuestro patrimonio, sino que es una necesidad primaria. Necesitamos conocer y percibir nuestro pasado y su trayectoria para entender nuestro presente, nuestra realidad en toda su extensión. El estado

1. Si bien el uso del concepto bienes culturales tiene dos precedentes inmediatos que han de mencionarse. El primero es la Convención para la Protección de los Bienes Culturales en caso de Conflicto Armado firmada en La Haya en 1954, mientras que el segundo son las conclusiones de la Comisión Franceschinni, un grupo de expertos que, secundados por el Parlamento italiano, propuso en 1967 las bases para una reforma legislativa en materia de bienes culturales en Italia. Agradecemos a los revisores anónimos la puntualización. 
español satisface principalmente tales necesidades en base al artículo 46 de la Constitución de 1978.

Ahora bien, no podemos perder de vista el origen burgués de esta necesidad que simboliza en el presente una serie de bienes heredados del pasado. Será la Revolución Francesa y la posterior consolidación durante el siglo xix del estado-nación en el mundo occidental la que, ante la necesidad de legitimarse bajo formas laicas, acuda a la historia. Este proceso es especialmente intenso durante el periodo de 1870 a 1914, que Hobsbawm (1983) define, para Europa, como de producción en masa de tradiciones. El patrimonio fue el elemento tangible que mejor sincretizaba y suponía un correlato a la geografía e historia nacional que entonces comenzaba a desarrollarse y a difundirse de manera hegemónica por escuelas y universidades. El estado español defendió dicho patrimonio mediante, en un primer momento, su protección y catalogación como monumentos nacionales, creando todo un corpus legal que se fue enriqueciendo a lo largo del siglo xx en una cadena ininterrumpida hasta nuestros días (Becerra García, 1999; Bermejo Barrera, 2007; Rivera Blanco, 2010).

No obstante, la propia configuración de tales políticas de tutela patrimonial es contradictoria, y lo es debido a la naturaleza del régimen político-económico bajo el que se produce y su ideología dominante. Las crisis de este sistema evidencian la tesis que aquí se expone.

Así, frente a esta vocación universal y democrática que empapa la construcción teórica del patrimonio histórico, afrontamos una realidad política y socioeconómica, especialmente desde la década de 1970, clasista, injusta y desigual, lo que impide aplicar tales criterios en toda su profundidad y coherencia. Ello, en directa relación con la forma de hacer ciudad, de habitarla y de entender sus espacios públicos (fundamentales en la ciudad histórica), se ha denunciado desde la geografía crítica en diferentes casos y experiencias (Fernández Salinas, 2003; Belina, 2011; Jover Báez, 2012). Entendemos como causa de la producción y reproducción de estas desigualdades una falta de justicia social, no sólo desde una perspectiva social e histórica, sino, como propone Soja (2010), también geográfica. El mismo autor apunta así como una institución como el Estado integra, concreta y objetiva en un marco social capitalista, que es estructuralmente injusto, nociones universales como la justicia, la libertad o la igualdad, con la consiguiente perversión que ello supone. En una línea similar se pronuncia Harvey (2001) cuando afirma que el Estado, a través de sus instituciones, al traducir estos principios, materializa ideas abstractas, y en el proceso se vale de su posición privilegiada para moldear su significado práctico. Ahora bien, tal posición privilegiada ni es estática ni constante; al contrario, está en permanente cambio. Ello responde a su enraizamiento dentro del esquema de la geometría del poder (Massey, 1992, 1993), concepto que abarca la espacialización de las relaciones sociales y económicas y sus estructuras internas y externas. La lucha por la dominación de tales relaciones y de las escalas donde se disputa su poder (Swyngedouw, 1997) ha adquirido una dinámica desequilibrada hacia la retórica económica en base a la penetración de los dogmas defendidos por la matriz neoliberal, 
que llega incluso a la amenaza al sistema democrático dentro del que se han desarrollado (Harvey, 2007).

En el contexto que describimos, caracterizado por la consolidación de la urbanización planetaria (Merrifield, 2013), el Estado ha instrumentalizado históricamente el patrimonio como artefacto cultural, para crear lo que Anderson (1983) llama comunidades imaginadas. Amparado en este marco ideológico y conceptual, y a pesar del sesgo discursivo del patrimonio en su función identitaria nacional, el avance teórico ha sido constante (Gómez-Mendoza, 2013). Causa y consecuencia de esto último es la aceleración de la reglamentación formal y legislativa del patrimonio en los países occidentales, especialmente a partir de la Convención para la Protección del Patrimonio Mundial Cultural y Natural de la UNESCO de 1972. Ello contrasta con los cambios que se producen en el seno del sistema a partir de la misma década de 1970, como comentamos supra. Resulta paradójico que avances en materia de tutela patrimonial coincidan con las transformaciones de corte postmoderno (Jameson, 1984; Soja, 1989), cuyos parámetros se orientan hacia la mercantilización de la cultura y con ella, el patrimonio. Es, siguiendo a Harvey (1989), la crisis económica de 1973 la que puso las bases para un reciclaje del capitalismo en el que se buscan mercados flexibles y cambiantes, así como una producción y consumo diversificados. La matriz neoliberal impone, de forma aun más acelerada desde la caída del Muro de Berlín, la cultura del consumo. La organización social, las instituciones, las escalas como espacios abstractos en disputa, y las ciudades como espacios físicos donde tales procesos se concretan, todos son dominados en distinto grado por la ideología neoliberal. Esta victoria de la lógica del capital — que supone una derrota ideológica y material de los grupos sociales dominados - se refleja por ejemplo a nivel institucional en las medidas de control del gasto público o "austeridad», combinadas con políticas de desregulación de los mercados financieros, siguiendo directrices de instituciones supraestatales como la UE, el BCE o el FMI (Peet, 2011; Navarro y Torres López, 2012). Otro ejemplo es la asunción del modelo empresarial de producción en serie aplicado a un principio constitucional como es la vivienda (artículo 47 de la Constitución), que se convierte en mercancía, bien intercambiable y por tanto susceptible de especulación.

En esta dinámica el discurso patrimonial es progresivamente desposeído de su carga cultural o social, distorsionándose hasta convertirse en recurso. Se alinea entonces con la perspectiva productivista, en tanto que elemento rentable económicamente, eliminando de esta forma toda la potencialidad crítica que podría tener vinculado a una variedad de discursos: histórico, social, geográfico, antropológico, etc. (Bermejo Barrera, 2006, 2007). En la práctica, y basado en lo anterior, el Estado, en sus diferentes escalas, ha dirigido su política patrimonial decidiendo qué es considerado como tal. Al mismo tiempo, la lógica del capital se ha ido introduciendo, en lo que a las ciudades históricas respecta, también en los planes urbanísticos, con el fin de hacer de estas un producto que compita mejor en el mercado globalizado. La proliferación de ciudades-marca como espacios urbanos reinventados hacia la consecución 
de un modelo de ciudad atractivo a los capitales e inversores internacionales, es quizás la plasmación más evidente de cómo el patrimonio se ha utilizado con un fin mercantilista, dejando a un lado la opinión de actores sociales subalternos (plataformas, asociaciones, movimientos sociales, etc.), que proponen por regla general otro modelo alejado de las nociones capitalistas (Rodríguez Medela y Salguero Montano, 2012).

Es así que este ideario neoliberal ha afectado al patrimonio de las ciudades históricas tanto en forma como en fondo. Con la primera se hace referencia a la incapacidad de las administraciones públicas a la hora de preservar eficientemente el patrimonio existente. Esto ocurre en dos sentidos. Por un lado, los gobiernos locales, regionales y estatal se desentienden de las necesidades sociales y demandas de colectivos subalternos, que suelen ir unidas a reivindicaciones patrimoniales de incidencia directa o indirecta (cuestiones de vivienda, espacios públicos, centros vecinales, etc.) ${ }^{2}$. Por otro lado, se han desarrollado nuevos modelos de gestión público-privados, o privados en su totalidad. El problema se observa cuando, en la coyuntura actual, la iniciativa privada no es capaz de hacerse cargo del patrimonio más allá de aquel que, principalmente por la vía turística, le reporta beneficios. Relacionado con esto, y en cuanto al fondo, se observa un preocupante giro teórico. Entender el mismo mediante criterios economicistas, olvidando la propia esencia de su tutela, sus valores y por tanto su destino público, supone traicionar a las que son, en última instancia, las titulares legítimas del patrimonio: las personas y, en su conjunto, la sociedad.

Así, ciudadanos y grupos sociales ven relegada su participación en la ciudad histórica a una mera relación pasiva, de consumidor. Esto es, cuales turistas que han de disfrutar bienes que en gran medida se encuentran descontextualizados y/o desvirtuados (Russo, 2002; Juan i Tresserras, 2004). De esta forma, no sólo se ha eliminado la potencialidad crítica de los mismos, sino también su carácter educativo en valores democráticos tales como solidaridad o pluralidad; e incluso, en ocasiones y como señala Castillo Ruiz (2007), rompiéndose la "continuidad entre pasado y presente» que lo define. El patrimonio urbano se ha visto y aun se ve, por lo general, socavado de su capacidad de contendor cultural, de totalizador de las relaciones sociales y, en última instancia, de motor para el cambio social. La causa la encontramos en la capacidad que el sistema ha desarrollado para sojuzgar las relaciones políticas, institucionales, económicas y sociales en todas las escalas. En consecuencia, los movimientos sociales, auténtica fuente de la innovación social al no estar sujetos a las reglas de juego establecidas, como los definiría Castells (1983), han de encontrar las diaclasas, aquellos pequeños espacios (tanto materiales como argumentales) no ocupados por el sistema imperante para llevar a cabo sus objetivos, generalmente comprometidos con los valores democráticos que, en teoría, inspiran los sistemas políticos occidentales.

2. Varios son los ejemplos que se podrían citar. En Sevilla, destaca el caso del Centro Vecinal Pumarejo así como la lucha vecinal por un espacio público en el centro histórico como es la Alameda de Hércules (Barber et al., 2006; Díaz Parra, 2010). 


\section{El contexto geohistórico del urbanismo gaditano en los siglos $\mathrm{xx}$ y XXI}

En esta búsqueda que acabamos de mencionar, y en un contexto urbano histórico como el de Cádiz, se producen experiencias de recuperación y resignificación social de espacios históricos, en este caso un inmueble, como es el Centro Social Okupado Autogestionado (CSOA) La Higuera. Para comprender esta experiencia, así como la situación que vive el patrimonio de la ciudad, consideramos que es indispensable abordar, desde un enfoque social, el contexto geohistórico del urbanismo gaditano. Este último viene determinado por su adecuación a las necesidades de las élites económicas y políticas, y a su ideología dominante, aunque mediatizado por una relación con la coyuntura económica nacional e internacional, los nichos de mercado o de inversión en auge - directamente relacionado con el movimiento del sistema-mundo capitalista-, y las reivindicaciones de los movimientos sociales y políticos.

Cada periodo y coyuntura histórica ha ido dejando en Cádiz, en base a impulsos económicos y sociales, una serie de rasgos urbanísticos definitorios que explican la conformación de la ciudad actual. A nivel general, el modelo urbano está condicionado por la escasez de espacio y el marcado carácter comercial y marítimo. Cádiz se beneficia de su emplazamiento, en la bahía homónima, y su situación en el sur peninsular, factor que explica, en gran parte, su papel como puerto comercial. No obstante, no es posible entender la fisonomía urbana del casco histórico de Cádiz sin mencionar ciertos procesos desarrollados a partir de la Edad Moderna. Entre ellos, el continuo afán de la monarquía hispánica por defender y cercar la ciudad - fundamentalmente tras el asalto anglo-holandés de 1596 y definitivamente tras el traslado de la Casa de Contratación y la cabecera del comercio de Indias en 1717_; o la caracterización burguesa y liberal de la ciudad, espoleada por el comercio y su conformación cosmopolita, que explica, tanto la riqueza inmobiliaria —unida al carácter rentista de la misma-, como los acontecimientos liberales de la primera mitad del siglo XIX.

Dejando a un lado estos episodios, un momento de gran trascendencia será la transición del siglo XIX al xx, cuando asistimos a una revitalización de la vida económica, social y urbanística de la ciudad. Paradójicamente, esto ocurre como reacción al Desastre de 1898, con la pérdida de las últimas colonias ultramarinas y el definitivo declive del puerto gaditano, que ya se gestaba durante el siglo XIX. El regeneracionismo, que como movimiento cultural y social nace desde la década de 1880, tiene en la ciudad consecuencias prácticas en la primera década de 1900: se potencia el Plan General de Extramuros para la expansión de la ciudad fuera de las Puertas de Tierra (1904); lo que va unido al Plan de Urbanización, que, acogiéndose a la Ley de Ensanches, derriba gran parte de las murallas y glacis, y acomete proyectos urbanísticos como el Paseo de Canalejas o la Plaza de España (1906-1912) o la apertura de vías para el tráfico rodado y el tranvía (1906), entre otras (Millán Chivite, 1993; Bustos, 2005).

Así, la primera mitad del siglo xx supone un momento de fuerte dinamismo económico y urbanístico. Fundamentalmente, observamos una diversi- 


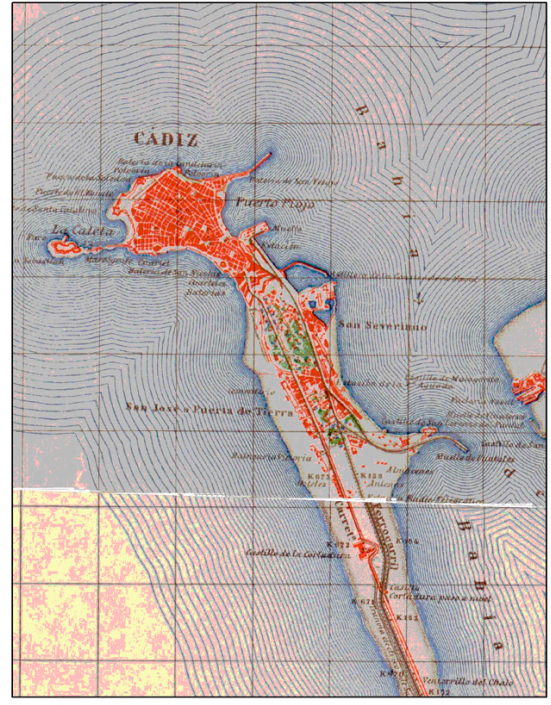

A

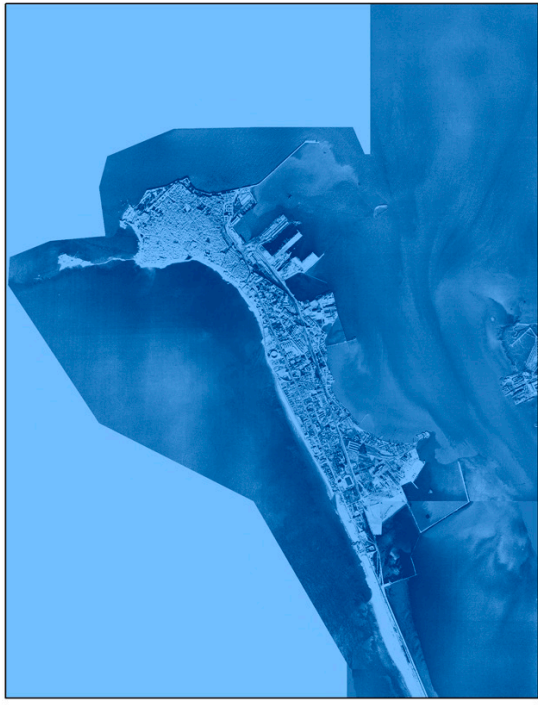

$2 \mathrm{Kms}$

Figura 1. Cádiz, a la izquierda, detalle del mapa de Andalucía 1:50.000 del Estado Mayor del Ejército Alemán (1940-1944), y a la derecha detalle de la ortofoto del vuelo americano (1956-1957).

Fuente: elaboración propia a partir de Infraestructura de Datos Espaciales de Andalucía.

dad de usos en la zona de extramuros, hacia donde se expande la ciudad de forma acelerada. En el istmo más allá de las Puertas de Tierra existían áreas residenciales para capas poblacionales modestas como las barriadas de San Severiano, Puntales o San José, si bien ahora se consolidan y crecen. Por otro lado, encontramos zonas de expansión residencial que responden a parámetros próximos a las ideas urbanas derivadas de la ciudad-jardín, combinadas con algunos ejemplos de arquitectura racionalista (Mosquera Adell, 1999) para capas altas de la población. Estas se intercalan con hoteles, ventas y elementos simbólicos y de recreo para la clase dominante, que dirigía este proceso, como el Balneario (1907); todo ello en primera línea de playa y unido a una incipiente visión turística de la ciudad. En cuanto a las actividades productivas, se observan varios ejemplos diseminados, como la fábrica de coches Ford, los depósitos de tabaco, las bodegas Lacave, la telegrafía sin hilos o los mismos astilleros, que datan del siglo XIx. Ahora bien, este avance en extramuros se verá coartado por la explosión del polvorín de la Armada en 1947 (Aparicio Florido, 2009), que será el punto de inflexión hacia el definitivo desmantelamiento de la influencia militar y un avance algo más ordenado a lo largo de la segunda mitad de siglo. En aquella parte del centro histórico tradicionalmente destinada a vivienda para sectores populares, condicionada por su exposición a 
los vientos predominantes (zonas de la Viña, la Caleta), vemos la proliferación de infraviviendas y la consolidación, en definitiva, de un amplio sector para clases bajas en los terrenos desalojados por los usos militares - en el barrio de El Balón- (Millán Chivite, 1993; VV.AA., 2002).

La segunda mitad del siglo xx se caracteriza por la definitiva ocupación urbanística del espacio extramuros hasta el comienzo de las dunas de Cortadura. En general, tal zona se había ordenado en el Plan Urbanístico de 1948 como espacio dividido por la vía del tren. Por un lado, la zona de esparcimiento, turismo, viviendas para la burguesía, etc., en la franja occidental, a lo largo de la playa, en línea con lo ya urbanizado en el periodo anterior. Por otro lado, una zona industrial y portuaria (con los nuevos Astilleros del INI - Instituto Nacional de Industria) en la franja oriental, centrada en revitalizar económicamente la ciudad. No obstante, vemos como en el área industrial, debido al fracaso de la política franquista y municipal, se intercalará una escasa actividad económica con una desordenada urbanización de viviendas que absorbe tanto los sectores pobres que son desalojados de los masificados barrios obreros del centro, como el éxodo rural en marcha en aquel momento. Numerosos barrios con pésimas condiciones de habitabilidad y servicios nacen en extramuros durante las décadas de los años cincuenta, sesenta y setenta, fomentado por la actuación especuladora del sector privado de la construcción, con la connivencia del sector público. Como evidencia Mato Ortega (2005), este plan urbanístico de 1948 es clave en la reproducción de problemas de conflictividad social que se observan hasta hoy en día, debido al poco interés de las políticas públicas por aquellos sustratos poblacionales depauperados de clase trabajadora.

El proceso de creación de una ciudad turística en lo que hoy se ha convertido Cádiz, si bien encuentra sus precedentes a comienzos del siglo xx, comienza en los años ochenta debido al proceso de reestructuración socioeconómica fruto de la crisis de 1973, coincidiendo con el nuevo papel que la UE designaba al estado español en la división económica internacional (Navarro, 2006). Como en otras zonas del país, astilleros y actividades portuarias y comerciales debían quedar en un segundo plano, por lo que se potenciaron especialmente los sectores turístico e inmobiliario; aunque en Cádiz la trayectoria fue distinta en comparación con otras áreas costeras. La falta de espacio para construir, unida al crecimiento de la burbuja inmobiliaria y la carencia de oportunidades laborales llevan al incremento de los precios de vivienda y al mismo tiempo al descenso poblacional, continuado desde $1996^{3}$. Este proceso se puede poner en relación, por ejemplo, con la creación de la marca urbana Cádiz-2012, de la que acaba de salir la ciudad con un saldo socio-económico pésimo, fruto de la falta de oportunidades laborales y económicas (Rodríguez Medela y Salguero Montano, 2012). La creación de un segundo puente sobre la bahía y la realización de obras con escaso trasfondo social (remodelación del estadio de fútbol, reorganización de espacios públicos como plazas y parques, etc.), van

3. De 1996 a 2010, Cádiz perdió una media de 1.412 habitantes al año (Datos del Padrón Municipal obtenidos a través del SIMA-Sistema de Información Multiterritorial de Andalucía). 
de la mano de la explotación de un patrimonio urbano que pocas veces cumple funciones sociales o culturales, como vemos en la cantidad de viviendas vacías en manos de especuladores ${ }^{4}$. Otra serie de edificios quedan abandonados o sin uso, como vemos en el caso de la Aduana, los Depósitos de Tabacalera, la antigua Casa Cuna, etc. Si bien se han realizado rehabilitaciones de edificios y construcciones en la ciudad en los últimos años, normalmente estos tienen una finalidad lucrativa y no va vinculado directamente a necesidades vecinales que demandan nuevos servicios o prestaciones.

La falta de conciencia social en lo que respecta a las actuaciones urbanísticas, patrimoniales o arquitectónicas se repite durante todo el siglo $\mathrm{xx}$, primando el beneficio de industriales y comerciales de la ciudad que, por lo general, copan las instituciones públicas. No obstante, la llegada de la democracia introduce una serie de cambios, en gran medida por las luchas vecinales que se suceden antes y durante la Transición, mientras que el Estado de las autonomías también tendrá sus efectos positivos. Por ejemplo destacan las intervenciones a cargo de la Junta de Andalucía: en 1989, con las «Barriadas de Actuación Preferente», así como el programa de rehabilitación de viviendas del centro histórico a partir de 1999, que durante la primera década del siglo XxI ha rehabilitado más de 5.000 viviendas (Rodríguez Galadí y Salmerón Escobar, 2010). Ambas, en cualquier caso, coinciden tardíamente con dos de las olas gentrificadoras que Smith (2002) señala como estrategias urbanas cruciales en la alianza neoliberal por la que gobiernos urbanos y regionales de todo el mundo se doblegan ante intereses privados de diferente clase. Tales alianzas se producen en pos de la maximización del beneficio, que en Cádiz se entiende aplicando la ecuación turística. Bajo este prisma hay que observar el Plan URBAN de la Comisión Europea que entre 1995 y 1999 tematizó el histórico barrio del Pópulo, ya que lo convirtió a través de la regeneración de sus espacios públicos y la recuperación de algunos inmuebles en uno de los epicentros de la marca turística gaditana, lo que desencadenó en consecuencia procesos de gentrificación (Egea Jiménez et al., 2013). Las políticas municipales que se comentan, en el tránsito del gobierno del PSOE (alcaldía de Carlos Díaz) por el actual del PP (alcaldía de Teófila Martínez), se encuadran en la dinámica neoliberal que desde el final de la década de 1990 ha inspirado cuando no dirigido, en distinto grado de intensidad, la política de los sucesivos gobiernos nacionales y autonómicos de ambos partidos.

En definitiva, la política municipal de las últimas décadas, también la ejecutada en el centro histórico, está subordinada al capital y no resuelve con precisión y amplitud los problemas que en este espacio se dan. Tan sólo hace concesiones parciales, fragmentarias, sin profundizar en los aspectos socio-eco-

4. En concreto, según datos del Censo de Población y Vivienda (extraído del SIMA), en Cádiz había en 2001 un total de 5.473 viviendas familiares vacías. Asimismo, la siguiente noticia de El Diario de Cádiz (<http://www.diariodecadiz.es/article/cadiz/1496750/deshabitadas. html>) habla de 102 fincas — $80.000 \mathrm{~m}^{2}$ — vacías en el casco histórico, en abril de 2013 [Consultado: 4/02/2014]. 


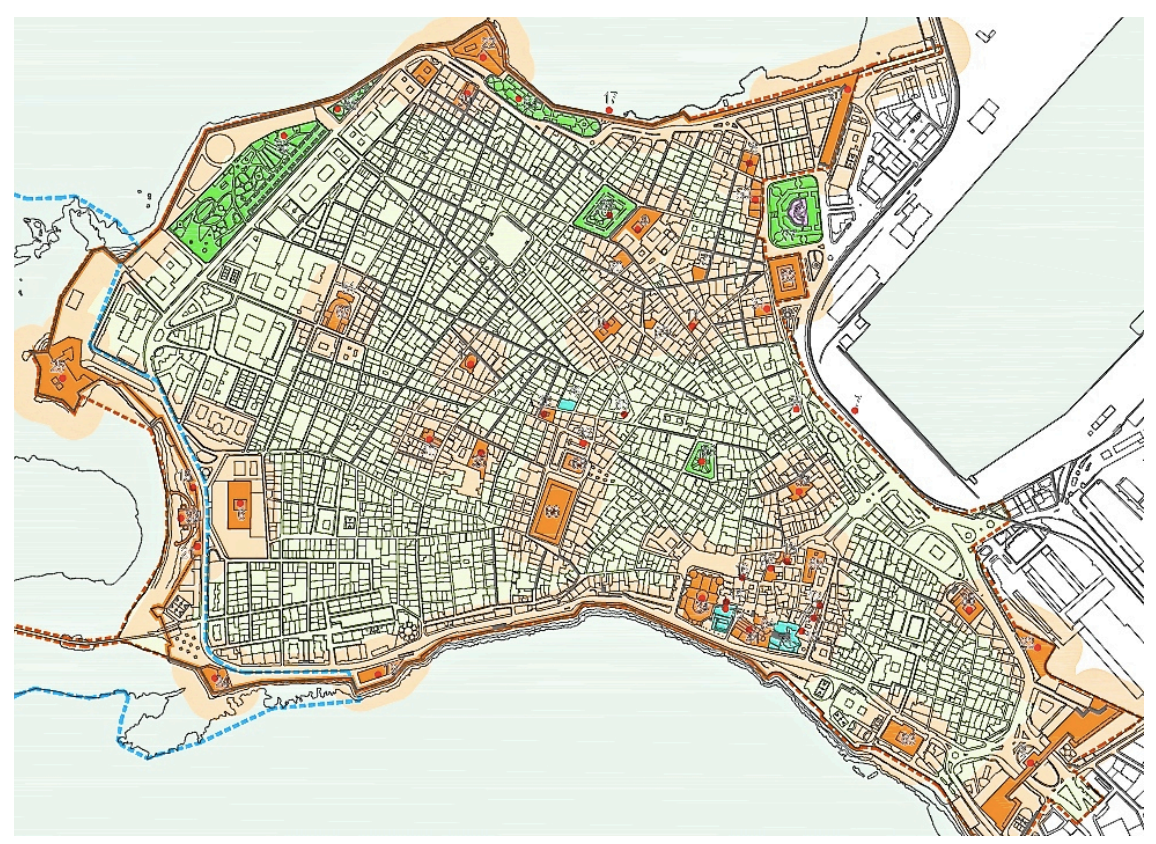

Figura 2. Conjunto Histórico de Cádiz (delimitación en línea discontinua naranja).

Fuente: PGOU (2011), Plano de Ordenación 1-4, de Protección Patrimonial (imagen con colores mejorados).

nómicos en juego. Esta falta de sensibilidad es manifiesta cuando se observa que, mientras que el planeamiento general ha sido renovado en las últimas décadas (1984, 1995, 2011 —este último aprobado definitivamente, de manera parcial5-), el Planeamiento Especial de Protección del Conjunto Histórico vigente sigue siendo de $1985^{6}$. En definitiva, el resultado es un nuevo paisaje urbano de edificios recuperados y espacios públicos recualificados que, al mismo tiempo, hace aumentar las rentas urbanas y con ellas se redistribuye el tejido social en función de su poder adquisitivo, reproduciendo las injusticias socio-espaciales.

\section{Movimientos sociales y vecinales en la encrucijada urbanística y patrimonial gaditana. La okupación como respuesta}

Ante la situación que se describe, la ciudadanía, repartida en diferentes colectivos y movimientos, se ha otorgado un mayor protagonismo, desde el momento

5. Orden de la Consejería de Obras Públicas y Vivienda de la Junta de Andalucía de 24 de noviembre de 2011. Boletín Oficial de la Junta de Andalucía, no 73, de 16 de abril de 2012.

6. El Conjunto Histórico-Artístico fue declarado, en base a la Ley de Patrimonio HistóricoArtístico de 1933, en 1972 (BOE de 2 de noviembre), y luego ampliado en 1978 (BOE de 25 de noviembre). 
que se ha alzado como un actor crucial en la vida de su ciudad. Es la ciudadanía más consciente, aquella que pone de relieve la mencionada pérdida de soberanía popular y se organiza en múltiples luchas, normalmente estructuradas localmente. En este contexto se comprende la okupación del CSOA La Higuera.

Si atendemos a la historia reciente de los movimientos sociales en Cádiz, es necesario citar el estallido social, que a nivel estatal, supuso el 15-M. A raíz del mismo han proliferado en la ciudad movimientos que, con un amplio ideario y diferente trasfondo político y social, no siempre coincidentes, han canalizado la protesta y han configurado un nuevo marco de lucha. Ello se ha producido principalmente en el espacio público, aunque también se ha trasladado a espacios privados, algo no habitual en una ciudad cuya experiencia okupadora es muy débil, especialmente en comparación con otras capitales andaluzas, como Sevilla, donde a los CSOA que se han sucedido en la primera década del siglo XxI, se suma el reciente fenómeno de las corralas, que, de forma menos organizada, acaba de extenderse a Cádiz ${ }^{7}$. Antes, destaca la experiencia en 2010 de la Casa Yoga, en extramuros ${ }^{8}$; y más tarde, con el fenómeno del 15-M, la okupación del abandonado Valcárcel (antiguo hospicio provincial y, posteriormente, colegio e instituto) y, toda vez acabada esa experiencia, la reciente de La Higuera.

A pesar de ello, las reivindicaciones en busca de un centro histórico más habitable en Cádiz no son recientes. Los procesos de tematización y gentrificación de este espacio urbano, producto de las políticas y programas de actuación que comentábamos anteriormente, sirvieron ya en la década de 1990 para reavivar el debate vecinal, aglutinar intereses y denunciar los efectos adversos de la voluntad municipal que busca reforzar la imagen histórica — con sus diferencias sociales que se comentan- como identidad de la ciudad para su venta en el mercado turístico. En este sentido, por ejemplo, la elección de inmuebles para intervenir ha seguido criterios no tanto sociales como de oportunidad y, obviamente, arquitectónicos, y se han priorizado edificios en avanzado estado de deterioro. Y, cuando esta se plantea, en muchas ocasiones se realiza bajo criterios meramente estéticos, esto es, dejando la fachada cuasi intacta y reformando el interior en su práctica totalidad - lo que se conoce como fachadismo-. Por su parte, la elitización de zonas del centro, directamente vinculada a lo que acabamos de comentar, se ha traducido físicamente en el fenómeno de las asustaviejas, o lo que es lo mismo, actuaciones — de inmobiliarias, propietarios y/o especuladores - cuyo objetivo es el desplazamiento de inquilinos fuera de sus viviendas (Egea Jiménez et al., 2013); ya sea activamente — mediante acoso directo, la amenaza - o pasivamente — abandonando el arrendador sus deberes dominicales con la finca, esperando la declaración de ruina-. La consecuencia, de nuevo, es la denunciada gentrificación.

No sorprende por tanto que el contexto y la coyuntura hayan culminado en okupaciones, recuperación de espacios privados, producción de lugares por

7. <http://www.lavozdigital.es/cadiz/v/20131129/cadiz/nueve-familias-okupantodo-20131129.html> [Consultado: 23/01/2014].

8. <http://andaluciainformacion.es/portada/? $\mathrm{a}=130825 \& \mathrm{i}=1>$ [Consultado: 18/12/2013]. 
y para los habitantes de Cádiz. Son nuevos espacios colectivos, utópicos, de convergencia y lucha. Estos procesos responden a la ruptura con la cultura del miedo, la que constantemente se apropia e identifica en un estadio tanto universal como concreto, la moral con la norma, materializando en ocasiones lo justo en injusto y viceversa (Swyngedouw, 2011). Tal cultura es la que impone, a través de su motor ideológico, los esquemas socio-espaciales que cada okupación rompe, y genera nuevas fantasías democráticas, que posibilitan el pensamiento crítico. Además, en el caso gaditano se da la circunstancia que, debido al extenso patrimonio en desuso, los espacios susceptibles a ser okupados normalmente tienen una elevada potencialidad histórica. Es así que cuando se producen, el patrimonio es recuperado bajo un discurso emancipado de su configuración tradicional, con una ideología diferente a la que emana de las instituciones y cuya trayectoria hemos descrito. Los espacios históricos okupados adquieren un carácter propio, otorgan una renovada significación colectiva; en definitiva, crean lugar - en la acepción más antropológica del concepto- En un reciente estudio, Pruijt (2013) trata de explicar la lógica de las okupaciones, y para ello las analiza y divide, basado en sus objetivos, en cinco tipologías no excluyentes: según sea por la necesidad primordial de vivienda, como estrategia alternativa de vivir, con fines mercantiles (aunque recalca, también alternativos, como un centro social - se usa el concepto inglés entrepreneurial - ), conservacionistas o políticos. Podemos decir que La Higuera respondía en distinto grado a todas estas categorías y las integraba, yendo más allá de la yuxtaposición de tipologías de okupación para denunciar la perversidad de la lógica que reside detrás, que fuerza a los habitantes de ciudades históricas en general y Cádiz en particular a ello, como es la lógica de la matriz neoliberal.

\section{El caso de «Manuel Rancés, 18»}

El número 18 de la calle Manuel Rancés, donde se situaba el CSOA La Higuera, es así un caso que escenifica la propia historia del urbanismo gaditano. El edificio, abandonado desde el año 2006, fue recuperado por un grupo de personas que, mediante su actuación, consiguieron darle un uso social y de vivienda.

El inmueble es una casa-palacio datada entre el siglo XVII y XVIII ${ }^{9}$, que presenta unas características arquitectónicas y artísticas excepcionales: del barroco antiguo, la primera galería del patio está sustentada por una solución de viguerías cruzadas situadas en las esquinas del mismo que permite la ausencia de columnas. Como elementos en piedra, destacan el doble brocal de pozo situado en el patio y la portada barroca con mármol genovés (Alonso de la

9. Encontramos diferentes fechas de datación del edificio (Alonso de la Sierra et al., 2005: 121; Jiménez Mata y Malo de Molina, 1995: 204; y el Plan Especial de Protección del Casco Histórico de Cádiz de 1985 [AMC, C. 5737, 14.0.11]), todas ellas de fines del siglo XVII y mediados del xviII, en torno al 1700, que hace que lo podamos encuadrar en la época de esplendor comercial de la ciudad. 
Sierra et al., 2005; Jiménez Mata y Malo de Molina, 1995). El edificio, de dos plantas y una entreplanta, consta asimismo de una torre mirador ${ }^{10}$, y se halla situado en el barrio de San Carlos — cerca de la actual Plaza de España—; cuando se construyó se encontraba junto a la muralla y el mar, en una posición privilegiada frente al puerto y la Aduana. De hecho, esta zona es la de mayor expansión burguesa en estos siglos.

La casa-palacio tiene como primer dueño relevante a Nicolás de la Cruz y Bahamonde, I Conde de Maule, comerciante chileno que se afinca en Cádiz en 1783 y que en un momento indeterminado compra la casa, junto con otras propiedades (APC, Sección Protocolos Notariales, CA 3202 [41-80]), lo que nos mostraría el carácter especulativo de la compra de inmuebles por parte de la burguesía comerciante. Tras dejar a su hija estos inmuebles en herencia en 1827, la casa pasa por una serie de propietarios hasta recaer, en la primera mitad del siglo xx en manos de Susana Burnham, hija de un banquero de La Habana, y su marido, Antonio Grosso Portillo. No conocemos el uso que se le dio a este edificio durante estos cien años, desde la primera mitad del XIX hasta la primera mitad del xx, pero podría apuntarse su interés especulativo, o, más probablemente, su transformación en corral de vecinos. En 1940 encontramos una referencia en tanto que a Antonio Grosso Portillo le fue concedida una licencia de obra para «renovar techo de madera por hormigón» (AMC, C. 2011, 2/1940). Su utilización como corral, que ha sido atestiguada desde el periodo franquista en comunicación verbal con vecinos, se confirma cuando el Plan Especial habla de ella en esos términos literales. Asimismo, podemos considerar que la actual disposición de las viviendas ocurre tras una intervención en la década de 1990, ya que en las obras realizadas de urgencia por el CSOA La Higuera se han encontrado evidencias de ello.

Fruto de su abandono durante años, fue declarado en 2006 como edificio a rehabilitar y las familias fueron realojadas, en principio temporalmente. No obstante, ninguna intervención en pos de su conservación se había realizado aún en mayo de 2012, fecha de la okupación. Tras pasar por varias inmobiliarias y promotoras, finalmente el inmueble entró en un proceso de embargo a favor de Catalunya Caixa que se ejecutó el 15 de octubre de 2013 y que supuso el desalojo de los vecinos y activistas del centro social. Hasta diciembre de 2014, miembros del CSOA La Higuera nos han informado que en el edificio no se han producido trabajos tendentes a la rehabilitación del mismo ${ }^{11}$. Esto ocurre con un inmueble que tiene el Grado 0 (máximo nivel de protección urbanística, calificado por el PGOU como «edificio monumental»). Hay que mencionar que este Grado 0 coincide en otros casos con la catalogación de Bien de Interés Cultural, máxima figura de protección patrimonial. La dejadez

10. La tipología de la torre y su tamaño nos podría indicar su anterioridad al resto de edificios del siglo XVIII que se encuentran en el barrio de San Carlos, donde se halla este edificio: especialmente las casas-palacio de las cuatro y de las cinco torres.

11. Es más, recientes noticias informan que la dejadez del inmueble continua, incluso se llegó a producir un incendio: <http://www.lavozdigital.es/cadiz/201412/11/incendio-manuelrances-fuego-20141211213704-pr.html> (Consultado el 18/12/2014) 


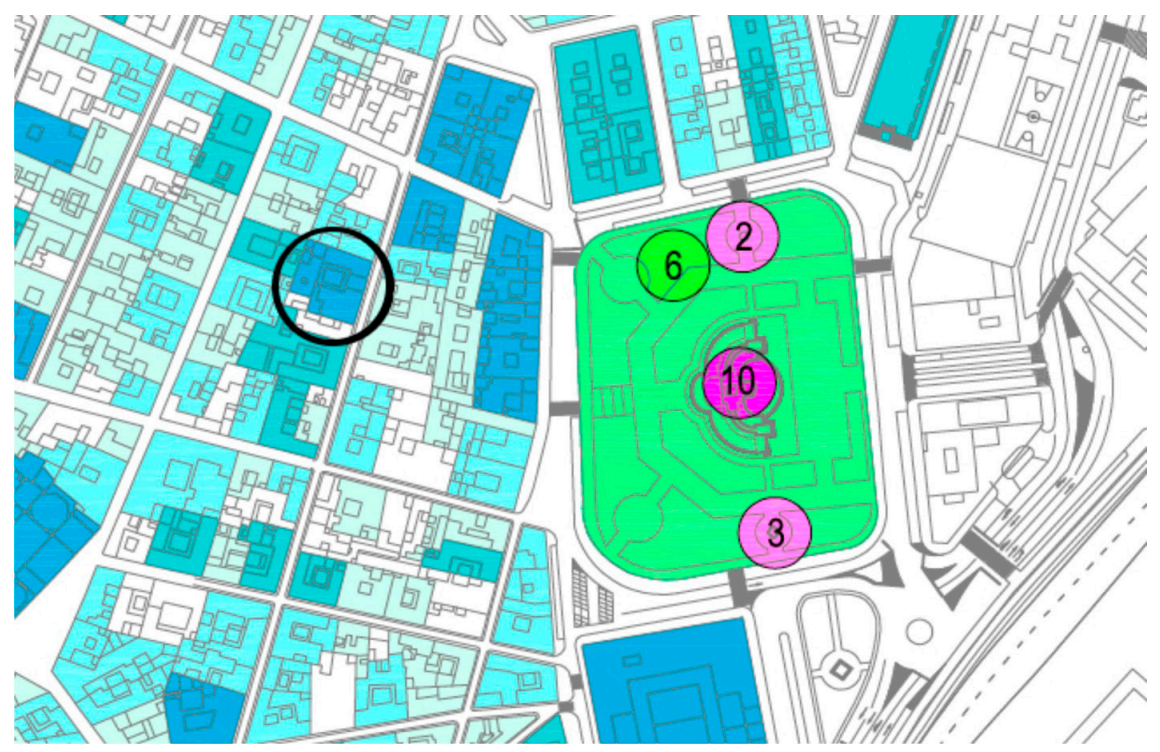

Figura 3. Situación y protección urbanística Grado 0 (en azul oscuro) del CSOA La Higuera

Fuente: PGOU (2011), Plano de Información 6-5, del Catálogo (imagen resaltada por los autores).

a la que estaba sometido y que lo dirigía hacia su desaparición, a pesar de la protección urbanística y patrimonial, pone de manifiesto que actualmente ni la iniciativa privada ni la pública (subordinada a intereses privados) aseguran una conservación efectiva del patrimonio.

Es por ello que el inmueble fue okupado, y se organizó un proyecto que aglutinaba viviendas y centro social ${ }^{12}$. La okupación tenía por tanto varias razones y objetivos. En primer lugar, ponía de manifiesto la existencia en Cádiz de cientos de viviendas vacías ${ }^{13}$, que contrasta con la dificultad existente especialmente para jóvenes y desempleados de acceder a una vivienda, que recordemos es un principio constitucional. Asimismo, se defendía una forma de organización y gestión de espacios asamblearia, autónoma y donde tienen cabida todo tipo de actos culturales, políticos, sociales, etc., sin pasar por filtros mercantilistas o bajo la tutela de instituciones que pueden sesgar o alinear ideológicamente ideas e inquietudes que impulsan tales actividades.

12. Noticias aparecidas en medios de comunicación [consultadas: $24 / 01 / 2014$ ]: <http://www. diariodecadiz.es/article/cadiz/1266526/grupo/okupas/toma/una/casapalacio/manuel/rances. html> <http:/www.lavozdigital.es/cadiz/20120524/local/cadiz/ocupacion-201205241844. html > <http://andaluciainformacion.es/cadiz/228920/los-vecinos-apoyan-la-ocupacin-concondiciones-cvicas/> <http:/www.lavozdigital.es/cadiz/v/20130329/cadiz/okupacion-silenciosa-20130329.html $>$.

13. Ver nota 4 . 

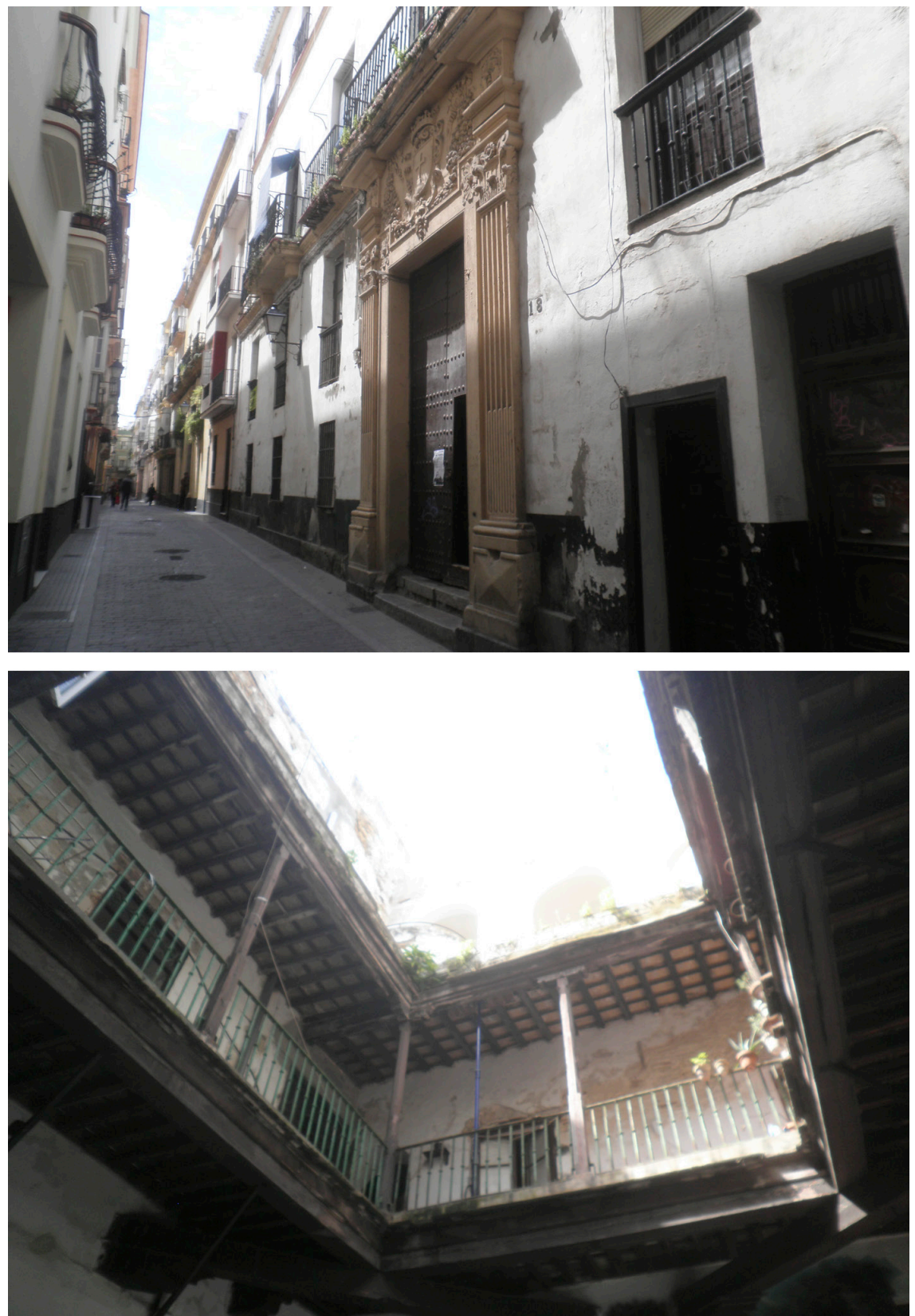

Figuras 4 y 5. Imágenes actuales de la casa-palacio. Arriba, fachada exterior. Abajo, balconada interior (al patio central) de la primera planta.

Fuente: de los autores, abril de 2013. 
Por ello, además de la propia limpieza y arreglo de la casa para asegurar su habitabilidad, se crearon espacios de debate y de intercambio cultural (visión de documentales, coloquios, conciertos, teatro), espacios para reuniones de colectivos y organizaciones, una tienda libre (los artículos eran intercambiados por otros o adquiridos sin contraprestación, si bien se podía dejar dinero de manera voluntaria) o un comedor popular. Al mismo tiempo, su uso como vivienda por algunos jóvenes mantenía viva la tradición de casa de vecinos que pivotaba en torno al patio del CSOA. La repercusión que a simple vista se observó (y que se constata en las noticias de la nota 12) es fruto de la buena sintonía que el vecindario y los comercios cercanos tenían con el nuevo uso del espacio. No obstante, sí debemos advertir que, tal como ocurre con muchos movimientos y espacios de creación colectiva, la participación del vecindario no fue tan activa como demandaba el propio colectivo.

En último lugar, destacaba el cambio de significado que sufrió el espacio, cuyo destino era meramente especulativo, y que pasó a convertirse en lugar de resistencia frente a las corrientes neoliberales que propugnan el beneficio como parámetro fundamental en la ciudad histórica. La decisión de la ciudadanía de preservar, instigada por la necesidad de vivienda y espacios de construcción colectiva, de forma directa su patrimonio supone una alternativa a la gestión de las instituciones, evidenciando a la vez la indefensión de aquel. Instituciones que mantienen una actitud pasiva tanto ante el progresivo abandono de edificios de valor patrimonial, con el riesgo incluso de su desaparición o derrumbe, como ante la destrucción del tejido social más humilde en centros históricos, que dota de carácter a estos espacios urbanos, y sin el cual el patrimonio material carecería de significado, de razón de ser.

\section{Conclusiones}

Consideramos los discursos patrimoniales como una construcción no inocente, que sintetiza intereses fundamentalmente privados (presentes también en los gobiernos e instituciones públicas), vehiculados en la extensión de la ideología neoliberal que convierte todo en susceptible de ser mercancía y reduce a los ciudadanos a meros consumidores, entes pasivos en la construcción cotidiana de la sociedad. La situación actual es especialmente paradójica en lo que respecta al uso, significación y disfrute del patrimonio. Desde el estallido de la crisis, el modelo de gestión del patrimonio muestra su verdadero rostro: una ingente cantidad de bienes inmuebles permanecen abandonados, debido a la primacía de la propiedad privada (fin especulativo y económico) sobre la utilidad social (fin identitario y funcional). El patrimonio se conceptúa en base a sus valores sociales, educativos y colectivos, orientado a las necesidades y servicios que la ciudadanía demande y reclame, de ahí su fin público y el progreso teórico-institucional en la materia durante las últimas décadas del siglo xx. Progreso que ha pasado de situarse en la órbita discursiva estatal, a estar secuestrado por la retórica neoliberal. El resultado es el modelo empresarial descrito, en el que los sectores públicos se alinean y pliegan a intereses 
privados, poniendo en evidencia las injusticias y desequilibrios de poder internos y de profundo arraigo en nuestra sociedad, que en última instancia cuestionan la misma democracia. Frente a ello, defendemos un modelo de gestión social y comunitaria del patrimonio, donde el discurso teórico tenga un auténtico reflejo en la práctica, sobre el territorio a escala local, a través de la generación de lugares de participación, creación, intercambio y expresión colectiva. Es por ello que ilustramos mediante el caso de «Manuel Rancés, 18» cómo los movimientos sociales son unos de los agentes más adecuados para realizar esto en la ciudad, resignificando el patrimonio y usándolo con fines prácticos. Su protagonismo es esencial. Así es como se construye la ciudad democrática moderna y se preserva la autenticidad en áreas urbanas históricas, a través de la directa defensa teórica y práctica por parte de los ciudadanos de sus derechos más fundamentales, entre ellos, a decidir sobre la forma de hacer ciudad, de crear espacios colectivos, y de diseñar discursos patrimoniales emancipados, que asuman las desigualdades socio-espaciales en la construcción de la ciudad histórica y que, partiendo de ahí, trabajen para el cambio.

\section{Referencias bibliográficas}

Alonso de la Sierra, Lorenzo; Alonso de la Sierra, Juan; Pomar Rodil, Pablo y Mariscal, Miguel Ángel (2005). Guía artística de Cádiz y su provincia. Tomo I: Cádiz y Jerez. Cádiz: Fundación José Manuel Lara y Diputación Provincial de Cádiz.

Alonso Ibáñez, María Rosario. (1992). El patrimonio histórico. Destino público y valor cultural. Madrid: Cívitas.

Anderson, Benedict (1983). Imagined Communities. Londres: Verso, 2006.

Arjones Fernández, Aurora (2007). Alö̈s Riegl. El culto moderno de los monumentos, su carácter y sus orígenes. Sevilla: Consejería de Cultura, Junta de Andalucía.

Aparicio Florido, José Antonio (2009). La noche trágica de Cádiz: testimonios inéditos de la catástrofe de 1947. Cádiz: Diputación Provincial de Cádiz.

Barber, Santiago et al. (2006). El Gran Pollo de la Alameda: una docena de años de lucha social en el barrio de la Alameda, Sevilla. Sevilla: Consejo Redactor del Gran Pollo de la Alameda.

Becerra García, Juan Manuel (1999). «La legislación española sobre el Patrimonio Histórico, origen y antecedentes. La Ley de Patrimonio Histórico Andaluz». En: V Jornadas sobre la Historia de Marchena. El patrimonio y su conservación (9-30).

$<$ http://www.bibliotecaspublicas.es/marchena/revistas/133/revista.htm> [consulta: 11 de junio de 2013].

Belina, Bernd (2011). «Ending public space as we know it». Social Justice, 38 (1-2), 13-27.

Bermejo Barrera, José Carlos (2006). Ciencia, ideología y mercado. Madrid: Akal.

- (2007). Moscas en una botella. Cómo dominar a la gente con palabras. Madrid: Akal.

Borón, Atilio (2003a). «Poder, "contrapoder" y "antipoder”. Notas sobre un extravío teórico-político en el pensamiento crítico contemporáneo». Chiapas, 15. México D.F.: Clacso. 
- (2003b). Estado, capitalismo y democracia en América Latina. Buenos Aires: Clacso.

Bustos Rodríguez, Manuel (2005). Cádiz en el sistema atlántico. La ciudad, sus comerciantes y la actividad mercantil (1650-1830). Madrid: Sílex.

Castells, Manuel (1983). The city and the grassroots - A cross cultural theory of urban social movements. Berkeley: University of California Press.

Castillo Ruiz, José (2005). «Libros que han hecho historia: el culto moderno a los monumentos». Revista Patrimonio Cultural y Derecho, 9, 341-345.

- (2007). «El futuro del patrimonio histórico: la patrimonialización del hombre». Revista Electrónica de Patrimonio Histórico, e-rph.

<http://www.revistadepatrimonio.es/revistas/numero1/concepto/estudios/articulo. php> [consulta: 30 de mayo de 2013].

DíAz PARra, Ibán (2010). Sevilla, cuestión de clase. Una geografía social de la ciudad. Sevilla: Atrapasueños.

Egea Jiménez, Carmen; Nieto Calmaestra, José Antonio; Domínguez Clemente, Javier y GonzÁlez Rego, René Alejandro (2013). "Conflictos urbanos: enfrentando las decisiones de los planificadores en el centro histórico de Cádiz (Andalucía, España)». En: SÁnchez González, Diego y EgeA Jiménez, Carmen (coords.). La ciudad, un espacio para la vida: miradas y enfoques desde la experiencia espacial. Granada: Universidad de Granada, 93-108.

Fernández Salinas, Víctor (2003). «Vivienda modesta y patrimonio cultural. Los corrales y patios de vecindad en el Conjunto Histórico de Sevilla». Scripta Nova, vol. VII, 146(070).

<http://www.ub.edu/geocrit/sn/sn-146\%28070\%29.htm> [consulta: 20 de mayo de 2013].

Gianinni, Massimo S. (1976). «Los bienes culturales». Revista Patrimonio Culturaly Derecho, 9, 11-42, 2005.

Gómez-Mendoza, Josefina (2013). «Del patrimonio paisaje a los paisajes patrimonio». Documents d'Anàlisi Geogràfica, vol. 59/1, 5-20.

Harvey, David (1989). The condition of postmodernity. Oxford: Blackwell.

- (2001). Spaces of capital. Towards a Critical Geography. Edimburgo: Edinburgh University Press.

- (2007). Brief History of Neoliberalism. Oxford: Oxford University Press.

- (2012). Rebel cities: from the right to the city to the urban revolution. Londres: Verso.

Hidalgo, José Antonio (2005). La ciudad soñada: los grandes proyectos urbanisticos de Cádiz en el siglo XX nunca ejecutados. Cádiz: Quorum editores.

Hirsch, Joachim y KannankUlam, John (2011). "The spaces of capital: the political form of capitalism and the internationalization of the state». Antipode, 43(1), $12-37$.

Hoвsвawm, Eric (1983). «Mass-Producing Traditions: Europe, 1870-1914». En: Hobsbawm, Eric y Ranger, Terence (eds.). The Invention of Tradition. Cambridge: Cambridge University Press, 263-307.

JAMESON, Fredric (1984). El posmodernismo o la lógica cultural del capitalismo avanzado. Barcelona: Paidós, 1991.

Jessop, Bob (1990). State Theory. Putting the capitalist state in its place. Cambridge: Polity Press.

Jiménez Mata, Juan y Malo de Molina, Julio (1995). Guía de Arquitectura de Cádiz. Sevilla: Consejería de Obras Públicas y Transporte.

Jover BÁEz, Jaime (2012). «Del evento mundial al no lugar: ¿transformación planificada? El caso de Puerta Triana en Sevilla». En: Seminario Internacional sobre Eventos 
Mundiales y Cambio Urbano: actas preliminares. Sevilla, 26-28 de noviembre de 2012, 209-219.

JuAn i Tresserras, Jordi (2004). «La tematización de las ciudades: el uso de la cultura en las estrategias de desarrollo local y promoción del turismo urbano». Revista Turismo y Sociedad, vol. VI, 3, 71-85.

Massey, Doreen (1992). «Politics and space/time». New Left Review, 196, 65-84.

- (1993). "Power-geometry and a progressive sense of place». En: Bird, Jon et al. (eds.). Mapping the futures: local cultures, global change. Londres: Routledge, 59-69.

Mato Ortega, José Manuel (2005). «Urbanismo y problemática social en Cádiz. Una aproximación histórica». Trocadero, 17, 163-182.

MERRIFIELD, Andy (2013). "The urban question under planetary urbanisation». International Journal of Urban and Regional Research, 37(3), 909-922.

Millán Chivite, José Luis (1993). Historia de Cádiz. Vol. IV. Siglo XX. Del Cádiz hundido al Cádiz que resurge (1898-1979). Madrid: Sílex.

Mosquera Adell, Eduardo (1999). «Racionalismo arquitectónico y transformación de la ciudad contemporánea: la obra de Sánchez Esteve en Cádiz». En: Cuadernos del Instituto Andaluz del Patrimonio Histórico. La arquitectura moderna en Andalucía: un patrimonio por documentar y conservar. Granada: Comares, 136-157.

MuÑoz, Francesc (2008). Urbanalización: paisajes comunes, lugares globales. Barcelona: Gustavo Gili.

Navarro, Vicenç (2006). El subdesarrollo social de España. Causas y consecuencias. Barcelona: Anagrama.

- y Torres López, Juan (2012). Los amos del mundo. Las armas del terrorismo financiero. Barcelona: Espasa.

PeEt, Richard (2011). «Inequality, crisis and austerity in finance capitalism». Cambridge Journal of Regions, Economy and Society, 4, 383-399.

Poulantzas, Nicos (1978). Estado, poder y socialismo. Madrid: Siglo XXI, 1979.

Pérez Serrano, Julio (1992). Cádiz, la ciudad desnuda. Cambio económico y modelo demográfico en la formación de la Andalucía contemporánea. Cádiz: Servicio de Publicaciones de la Universidad de Cádiz.

Pruijt, Hans (2013). "The logic of urban squatting». International Journal of Urban and Regional Research, 37(1), 19-45.

Rivera Blanco, J. (2010). «Paisaje y patrimonio». En: Maderuelo, Javier (dir.). Paisaje y patrimonio. Madrid: Adaba, 11-29.

Rodríguez Galadí, José y Salmerón Escobar, Federico (2010). «Rehabilitación integral de los centros históricos andaluces». Ponencia presentada en conferencia: Edificación sostenible. Revitalización y rehabilitación de barrios (SB1Omad). Madrid, 28-30 de abril de 2010.

Rodríguez Medela, Juan y Salguero Montaño, Óscar (2012). Transformación urbana y conflictividad social. La construcción de la Marca Granada 2013-2015. Granada: Biblioteca Social Hermanos Quero.

Ruíz Nieto-Guerrero, María Pilar (1994). Urbanismo gaditano en tiempos de Carlos III: formación del Barrio de San Carlos. Cádiz: Servicio de Publicaciones de la Universidad de Cádiz.

Russo, Antonio P. (2002). "The vicious circle of tourism development in heritage cities». Annals of Tourism Research, 29 (1), 165-182.

Sмiтн, Neil (2002). «New globalism, new urbanism: gentrification as global urban strategy". Antipode, 34(3), 427-450. 
Soja, Edward (1989). Postmodern Geographies. The reassertion of space in Critical Social Theory. Londres: Verso.

- (2010). Seeking Spatial Justice. Minneapolis: University of Minnesota Press.

Swyngedouw, Erik (1997). «Neither global nor local». En: Cox, Kevin (ed.). Spaces of globalization: reasserting the power of the local. Londres: Gulford, 137-166.

- (2011). "Interrogating post-democratization: Reclaiming egalitarian political spaces». Political Geography, 30, 370-380.

VV.AA. (2002). Paisaje urbano y memoria. La ciudad de Cádiz en el siglo XX. Cádiz: Fundación Municipal de Cultura, Ayuntamiento de Cádiz.

\section{Archivos consultados}

Archivo General de Simancas (AGS)

Archivo Municipal de Cádiz (AMC)

Archivo Provincial de Cádiz (APC)

\section{Documentos legales}

PGOU - Plan General de Ordenación Urbana de Cádiz. Ayuntamiento de Cádiz, disponible en: <http://www.institucional.cadiz.es/area/Plan $\% 20$ General $\% 20 \mathrm{de} \% 20$ Ordenaci\%25C3\%25B3n\%20Urbana\%20\%2528PGOU\%2529/677> [consulta: 28 de junio de 2013]. 